$100 \%$ owing to some patients coming to pick up the medicines before the set date. The method used in this study could be improved with validated adherence questionnaires. Good adherence is necessary to achieve SVR and it is especially important with the new protease inhibitors drugs (boceprevir and telaprevir), due to the complexity of triple therapy, adverse reactions and the high cost. Therefore, hospital pharmacists should collaborate on it with pharmaceutical care clinics specialising in hepatitis C.

No conflict of interest.

\section{CPC-063 HOW DO PHARMACISTS DOCUMENT AND TRANSMIT THEIR INTERVENTIONS? A SURVEY IN SEVERAL FRENCH-SPEAKING COUNTRIES}

doi:10.1136/ejhpharm-2013-000276.520

'S Kabiche, 'C Fonzo-Christe, ${ }^{2} \mathrm{~S}$ Prot-Labarthe, 'B Guignard, 'T Sigrist, ${ }^{2} \mathrm{~F}$ Brion, ${ }^{2} 0$ Bourdon, 'P Bonnabry. 'Geneva University Hospital, Pharmacy, Geneva, Switzerland; ${ }^{2}$ Robert Debré Hospital, Pharmacy, Paris, France

Background The role of a clinical pharmacist in providing and transmitting drug information to other health professionals varies greatly between countries. There is no consensus on the most efficient way to document and transmit interventions and its effect on the implementation of recommendations in practise.

Purpose To describe and then compare the methodology of pharmacist's interventions (PIs) in each of the following French-speaking countries: France, Switzerland, Belgium and Quebec.

Materials and Methods 527 on-line questionnaires were distributed (276 in France, 47 in Switzerland, 92 in Belgium, and 112 in Quebec). They contained 36 questions about clinical pharmacy work, the ways of transmitting information and its documentation in the patient record.

Results 160 hospitals answered (total 30.3\%; France 33.7\%, Switzerland 44.7\%, Belgium 23.9\%, Quebec 21.4\%). In the Swiss hospitals, only $47.4 \%$ of pharmacists analysed pharmaceutical prescriptions while $97.4 \%$ did in France, $76.5 \%$ in Belgium and $100 \%$ in Quebec. The same trend could be seen while examining the pharmacist's presence on the wards: $42.1 \%$ in Switzerland, $58.4 \%$ in France, $85.7 \%$ in Belgium and $88.2 \%$ in Quebec.

Communications channels for PIs also differed depending on countries: Swiss pharmacists mainly used the phone $(56.7 \%$ of the cases), followed by personal visits (30.7\%). In France and Quebec the preferred methods were writing notes in the patient's record in respectively $39.1 \%$ and $36.4 \%$ of the cases, followed by phone calls in $25.4 \%$ and $32.4 \%$. In Belgium, the communication of PIs was most frequently done through personal visits (40\%).

Conclusions Pharmacist's interventions in terms of ways of transmitting drug information and its documentation differ among the 4 countries. Differences in the pharmacist's integration into the ward teams, access to the patient record file and to the medical prescription probably explain the heterogeneity of our results.

No conflict of interest.

\section{CPC-064 HOW IS IT BEST TO REPORT PHARMACEUTICAL INTERVENTIONS TO A MEDICAL TEAM? A CLINICAL RELEVANCE ASSESSMENT}

doi:10.1136/ejhpharm-2013-000276.521

${ }^{1} \underline{C}$ Di Fiore-Fave, 'E Bouvet, 'M Vié, ${ }^{2} \mathrm{P}$ Massip, ' $\mathrm{IM}$ Canonge. ${ }^{1} T o u l o u s e$ University Hospital, Clinical Pharmacy, Toulouse, France; ${ }^{2}$ Toulouse University Hospital, Infectious and tropical diseases medical department, Toulouse, France

Background The clinical pharmacy department has recently started working with the medical team of the infectious and tropical diseases department. A pharmacy student, supervised by a clinical pharmacist, cheques 28 patient prescriptions daily.
Purpose To evaluate the impact and quality of pharmaceutical interventions (PIs) issued over a period of 8 months.

Materials and Methods All interventions are recorded and coded according to the criteria defined by the working group of the French Society of Clinical Pharmacy [1]. A note of the relevance is attributed by the pharmacist to each PI, according to Bayliff and Einarson's scale [2].

Results In total, 1947 paper prescriptions were analysed. During this period, 980 patients were hospitalised, $133(13.6 \%)$ were identified as having 209 PIs. Physicians accepted 168 interventions (80\%), of which the pharmacist quantified the clinical relevance. A very significant clinical impact (level 2) was attributed to 36 PIs (21.5\%), a significant clinical impact (level 1) to 77 (46\%) and 54 PIs (32.5\%) had an informative objective (level 0). No interventions had a vital clinical impact (level 3).

For each level of relevance, the distribution of PIs was described according to the type of drug-related problems on the one hand and the type of pharmacists' recommendations on the other hand Highlighting the clinical impact of PIs increased the interest of physicians in pharmaceutical work. Consequently, they asked for pharmaceutical reports more frequently (twice a month instead of once a year).

Conclusions The results reinforce the idea that a regular presence in care encourages collaboration between pharmacists and health care teams.

\section{References}

1. Bedouch P, Charpiat B, Roubille R, et al, (2007). Site internet de la société française de pharmacie Clinique pour l'analyse des interventions pharmaceutiques: finalités, mode d'emploi et perspectives. J Pharm Clin 26(1), 40-4.

2. Bayliff CD, Einarson TR, (1990). Physician assessment of pharmacist's intervention: a method of estimating cost avoidance and determining quality assurance. Can J Hospi Pharm 43(4), 167-7.

No conflict of interest.

\section{CPC-065 HOW TO ASSESS MEDICATION ADHERENCE AMONG PATIENTS WITH RESISTANT HYPERTENSION TREATED WITH TWO DIFFERENT PHARMACOLOGICAL INTENSIFICATION STRATEGIES}

doi:10.1136/ejhpharm-2013-000276.522

${ }^{1} \mathrm{H}$ Beaussier, ${ }^{2} \mathrm{~F}$ Coudore, ${ }^{3} \mathrm{G}$ Bobrie, ${ }^{4} \mathrm{~S}$ Peyrard, ${ }^{5} \mathrm{~L}$ Tran, ${ }^{5} \mathrm{Y}$ Bezie, ${ }^{6} \mathrm{M}$ Azizi, ${ }^{2} \mathrm{P}$ Boutouyrie. ${ }^{1}$ Groupe Hospitalier Paris Saint-Joseph, CRC Pharmacie, Paris Cedex 14, France; ${ }^{2} \mathrm{HEGP}$ Service de Pharmacologie Clinique, Paris Cedex 15, France; ${ }^{3} H E G P$, Service de médecine vasculaire - Unité d'hypertension artérielle, Paris Cedex 15, France; ${ }^{4} H E G P$, URC, Paris Cedex 15, France; ${ }^{5}$ Groupe Hospitalier Paris Saint-Joseph, Service de Pharmacie, Paris Cedex 14, France; ${ }^{6} \mathrm{HEGP}$, CIC, Paris Cedex 15, France

Background Non-adherence to medicines and lifestyle are the main contributors to resistance to antihypertensive treatment (AHT). Various measures to assess medicines adherence (MA) among patients with resistant hypertension (RH) have been proposed but none is fully effective.

Purpose To assess MA with a new scoring system in RH patients included in a randomised controlled trial and the characteristics associated with low MA

Materials and Methods Patients with RH on 4 week-treatment with irbesartan $300 \mathrm{mg}+$ hydrochlorothiazide $12.5 \mathrm{mg}+$ amlodipine $5 \mathrm{mg}$, were randomised to either reinforcement of sodium depletion by sequential administration of spironolactone and other diuretics ( $A B$ group, $n=82$ ) or reinforcement of renin angiotensin system blockade by sequential administration of ramipril 5-10 mg and bisoprolol 5-10 mg ( $\mathrm{RB}$ group, $\mathrm{n}=82$ ) for 12 weeks. In accordance with the literature, 4 methods were used to evaluate MA: 1/ measurement of plasma irbesartan concentration (HPLC); $2 /$ measurement of urinary AcSDKP/creatinine ratio (UR) to evaluate ACE inhibitor exposure; $3 /$ last dose of medicine taken before visit; 4/pill 